\title{
Causes of Drug Addiction among Youth in Sylhet City of Bangladesh
}

\author{
Md. Abdul Ahad ${ }^{1}$, Dr. Mitu Chowdhury ${ }^{1}$, Dr. Indrajit Kundu ${ }^{2}$, Nishith Zahan \\ Tanny $^{3}$, Dr. M. Wakilur Rahman ${ }^{3}$ \\ ${ }^{1}$ Department of Agricultural and Rural Development, Sylhet Agricultural University, Sylhet- 3100, Bangladesh. \\ ${ }^{2}$ Department of Sociology, Chittagong University, Chittagong-4331, Bangladesh. \\ ${ }^{3}$ Department of Rural Sociology, Bangladesh Agricultural University, Mymensingh-2202, Bangladesh.
}

\begin{abstract}
The study investigated the causes of drug addiction among the youth and identified the problems faced by young drug addicts as consequences of drug addiction. In this study, through purposive sampling technique total 42 drug addicts were identified. Data was collected by using structured questionnaire, interview schedule and observation. To identify the causes of drug addiction, an analytical technique namely Influencing Causes Index (ICI) was used. The study depicts that curiosity was first and foremost reason and temptation by friends was the second reason behind drug addiction among youth. This study also revealed that highest $76.19 \%$ of drug addicts changed taking of drugs one after another to get adventure by tasting different drugs. About 88.09\% drug addicts feel being neglected by their relatives due to drug addiction. About $95.24 \%$ felt that they did not have any discipline in their daily life and 50\% have experienced some sexual problems due to their involvement in drug addiction. About $33.33 \%$ were faced some physical problems like kidney failure, lungs problem, heart disease, paralysis and psychological problem in pornography etc. Areas and context specific data are important for future policies and effective surveillance initiatives.
\end{abstract}

Key words: Cause, Drug Addiction, Youth, Sylhet City, Bangladesh.

\section{INTRODUCTION}

Despite the risk factors associated with drug abuse and addiction, drug addiction is quite common throughout the world. According to the World Drug Report (2010), the use of illicit drugs has increased throughout the world in recent years. It is also estimated that there were between 99000 and 253000 deaths globally in 2009 as a result of illicit drug use. Moreover, it was estimated that in 2008, there were 16 million injecting drug users worldwide and that of 3 million (18.9 percent) were living with HIV. Not only limited to this, the excessive, maladaptive, or addictive use of drugs for non-medicinal purposes also create a state, emotional and sometimes physical, characterized by a compulsion to take drugs on a constant basis to experience its mental effects. Drug addiction gives rise to dependence on both physical and psychological. The effects of drug addiction on an individual therefore form the basis for its cumulative effects on the family as well as in society.

The geographic location and availability of drugs made Bangladesh as one of the worst victims of drug (DNC, 2013). For instance, Bangladesh is situated in the central point between the 'golden triangle' (Myanmar, Thailand and Laos) and the 'golden crescent' (Pakistan, Afghanistan and Iran) and with its easy land, sea and air access is becoming a major transit point. Traffickers who supply drugs in the markets of Northern America, Africa, and Europe are routing their shipments through Dhaka, Comilla, Khulna, Sylhet and other routes in Bangladesh. The major illicit drugs available in Bangladesh are Opium (Heroin, Pethedine, Cocaine), Cannabis/Marijuana (Ganja, Chorosh, Bhang, Hashish), Stimulant (Yaba, Ectasy, Viagra), Sleeping pill (Tranquilizer,Diazepam etc.) and Cough syrup (Phensidyl, Dexpotent etc.) (DNC, 2013). The negative effects of drug addiction are enormous. For example, drug addiction is well identified as an important risk factor for family violence, particularly in cases involving serious violence, including homicide (Brookoff et al., 1997; Easton et al., 2000). Besides, drug addiction is related to destructive family behaviors, including child addiction and neglect (Bays, 1990; Davis, 1994; Famularo, Kinscherff \& Fenton, 1992; Sheridan, 1995) and incest (Hurley, 1991). Not only confined to this, an addicted person may show a decline in academic performance, frequently fails to attend classes, loses interest in school work and displays weakened motor coordination, poor health, and lack of interest in old friendships (Bawkin and Bawkin, 1972). Literatures show that there are a lot factors responsible behind drug addiction. A combination of physical addiction, sexual addiction, violence in the family, and a parental history of alcohol/drug use are correlated with youth substance addiction (Harrier et al. 2001). People take drugs to wade off boredom arising from monotony of life activities. The initial dosage level is always small and tolerable; prolong taking of drugs leads to progressive increase of the dosage level in order 
to produce the same effect. Youth like experimenting, the first experience may produce a state of arousal such as happiness and pleasure which in turn motivates them to continue (Isah, 2007). Substance addiction is frequently accompanied by some other problems, such as mental illness, domestic violence, economic difficulties, housing needs and residence in dangerous neighborhood environments (Semidei et al. 2001). There are more than 4 million drug addicts in Bangladesh and in Sylhet city it would be approximately one fourth of the total number. A lot of drug addicted patients are taking treatment in many rehabilitation centers of Bangladesh. In Sylhet region, there are more than 10 rehabilitation centers. Maximum patients who are taking the treatment in these rehabilitation centers are youth. Their age ranges from 16 to 40 years. This signals the size of drug addicts of this city. Many criminal activities are thought to be done by drug addicts to collect money to buy drugs. The police and other laws enforcing agencies take their action against drug addicts as per routine duty. Surveys also show that family disorganization and breakdown are also occurring due to the factors of drug addiction. School dropout students are also increasing everywhere in our country which may have connection with drug intake. For these reasons, it was very essential to conduct research in this field and that will be able to disseminate the negative consequences of drug addiction especially among youth.

The objectives of this study are to examine the causes of drug addiction among the youth and to identify the problems that young drug addicts are facing. As this topic is relatively sensitive and confidential, many respondents were reluctant to provide information about drug addiction. For this reason, the study was undertaken in selected drug rehabilitation centers of Sylhet city which were situated in Baluchar, Uposhahar and Patantula Point. This study has been done taking few respondents in limited time.

\section{METHODOLOGY OF THE STUDY}

Methodology is an indispensable and integrated part of any research. Considering the objectives of the present study, Sylhet City area was selected. Sylhet is a major city in north-eastern Bangladesh. At present, there are more than 10 drug rehabilitation centers in Sylhet City. Purposively among those rehabilitation centers, five drug rehabilitation centers were randomly selected for this study. From these drug rehabilitation centers, 42 respondents were drawn through purposive sampling technique. Survey and observation research design were used. According to Gall and Gall (1996), the main purpose of a survey is to use questionnaires and interviews to collect data from the participants about their characteristics, experiences and opinions, in order to generalize the findings to a population that the sample is intended to represent. The study included only those who were interested to participate. The data was collected from the sample respondents from January to March, 2016. After completing the each interview, the questionnaires were checked and verified to be sure that answer to each question was properly recorded. The collected data and information from survey were tabulated, summarized and analyzed according to the objectives of the study. Microsoft Word and Microsoft Excel were used for analyzing the data. Besides descriptive statistics, an analytical technique was also used. To identify the major causes of drug addiction, the Influencing Cause's Index (ICI) measure was used. This ICI measure was mainly followed from the idea of Constraint Facing Index (CFI) developed by J. C. Pandit and N. C. Basak (2013). To conduct this Influencing Causes Index (ICI), it is important to identify the dependent variables (influencing causes). Each dependent variable must have four response levels as 'very high', 'high', 'little' and 'not at all' including weight 3,2,1 and 0 , respectively. One respondent can select one response level for each variable. This scaling technique helps to get the percentages of response level categories of each aspect. The percentage of each response level category has been calculated in respect of overall respondents. To get ICI score for each aspect of influencing causes, the percentages of four response level of each aspect of influencing causes has been calculated through using the following formulae,

ICI $=\mathrm{P}_{\mathrm{n}} \times 0+\mathrm{P}_{1} \times 1+\mathrm{P}_{\mathrm{h}} \times 2+\mathrm{P}_{\mathrm{vh}} \times 3$

Where,

$\mathrm{P}_{\mathrm{n}}=$ Percentage of drug addicts are not having this as an influencing cause

$\mathrm{P}_{1}=$ Percentage of drug addicts having this as a little influencing cause

$\mathrm{P}_{\mathrm{h}}=$ Percentage of drug addicts having this as a high influencing cause

$\mathrm{P}_{\mathrm{vh}}=$ Percentage of drug addicts having this as a very high influencing cause

\subsection{Reason behind drug addiction}

\section{RESULT AND DISCUSSION}

To establish the reasons for drug addiction among youths, the researcher asked youth respondent (who were admitted in different drug rehabilitation centers) the questions related to causes of drug addiction. The respondents were allowed to respond to multiple-choice questions. Drug addicts usually face many enticing factors that are usually considered as the reasons for taking drugs. For specifying the most influencing causes behind drug addiction, ICI measure was used. The computed ICI and associated rank order on the basis of ICI values, taking all 13 causes items have been presented in Table 1 . 
Table 1: Rank order of 13 selected causes faced by the drug addicts

\begin{tabular}{|l|c|c|}
\hline \multicolumn{1}{|c|}{ Item } & ICI Score & Rank \\
\hline Curiosity & 199.98 & 2 \\
\hline $\begin{array}{l}\text { Encouragement from } \\
\text { friends }\end{array}$ & 192.84 & 3 \\
\hline Entertainment & 173.79 & 4 \\
\hline $\begin{array}{l}\text { Personal interest about } \\
\text { drugs }\end{array}$ & 171.44 & 5 \\
\hline To get relief from tension & 130.96 & 6 \\
\hline Surrounding environment & 116.66 & 7 \\
\hline $\begin{array}{l}\text { Frustration from family } \\
\text { issues }\end{array}$ & 114.30 & 8 \\
\hline Unemployment problem & 85.73 & 9 \\
\hline Others & 80.94 & 10 \\
\hline Easy access to drugs & 73.79 & 11 \\
\hline Estranged in love & 59.50 & 12 \\
\hline Unhappy in conjugal life & 57.12 & 13 \\
\hline $\begin{array}{l}\text { Drug addiction within the } \\
\text { family }\end{array}$ & 57.07 & \\
\hline
\end{tabular}

Study shows that curiosity of the drug addicts was ranked first (ICI Score: 199.98) among the 13 causes on the basis of ICI values, computed by using the responses of drug addicts. The cause item namely 'encouragement from friends' was ranked as second in all the 13 cause items. Entertainment was ranked as third cause of drug addiction among the youth. Table 1 also indicates that drug addicts were little encouraged by the reason of drug addiction within the family and this item was ranked as 13 , the lowest rank order among the all 13 cause items. Chronic drug addicts often changes drugs one after another. There are many reasons associated with this. It is important to note that each respondent had chosen multiple reasons. According to survey result, the most common causes are given in figure1.

Figure 1: Reason behind changing of drugs one after another by drug addicts

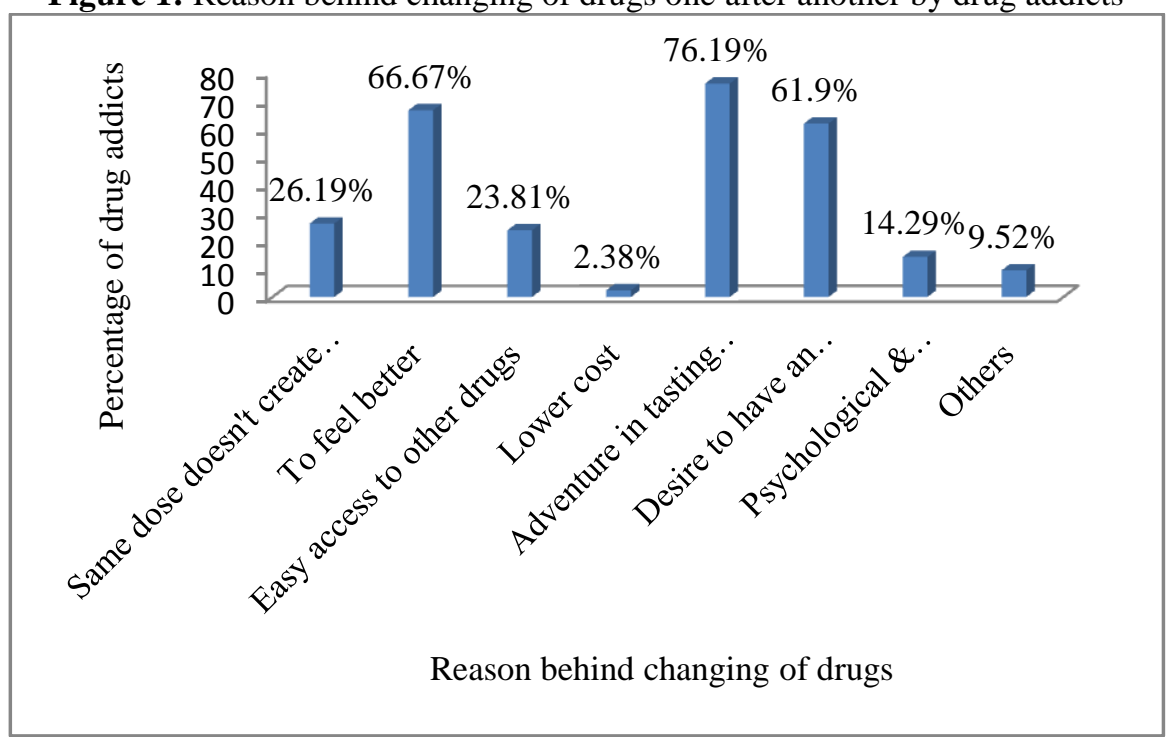

Study shows that the highest $76.19 \%$ of drug addicts changed the taking of drugs one after another to get adventure by tasting different drugs. To feel better, $66.67 \%$ of the drug addict continuously changed drugs. Only $2.38 \%$ drug addicts reported that they changed drugs one after another because of the lower cost of drugs. So, it is evident that, price acts as a minor factor in changing the different items of drugs.

\subsection{Major problems faced by drug addicts}

\subsubsection{Social and financial problems faced by drug addicts}

Drug addicts often face various kinds of problem. These are mainly social, financial, physical and psychological. Due to these problems, they are becoming alienated from their family and society. So, identification and analysis of the problems or constraints faced by drug addicts in our society is necessary to capture the whole scenario of drug addiction. The key problems that found through observing drug addicts are discussed in the following sections (figure 2). 
Figure 2: Major social and financial problems faced by drug addicts

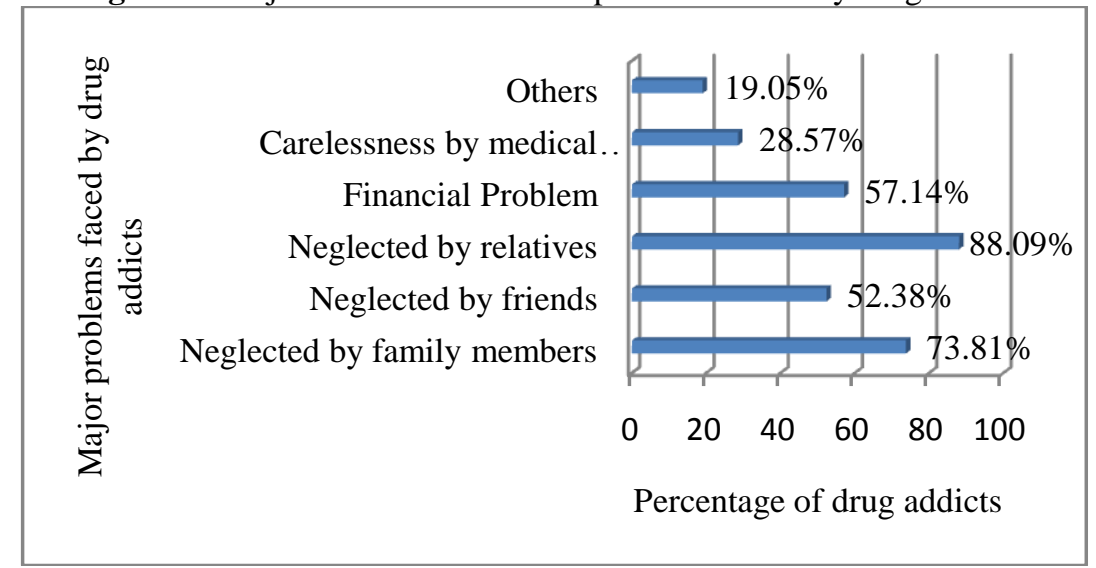

Study shows that $73.81 \%$ of the drug addicts were neglected by their family members and the highest $88.09 \%$ drug addicts felt being neglected by their relatives due to drug addiction. The ignorance makes them socially isolated and also pushes them towards continuation of drug intake. Consequently, this led to vicious circle of drug addiction.

\subsubsection{Physical or psychological problems faced by drug addicts}

There are a number of long-term physical and psychological effects of drug addiction that can easily turn a healthy man or women into a frail shadow of former self. It is important to note that drug addicts were facing multiple kinds of problem. The physical and psychological problems faced by drug addicts are represented in Figure 3.

Figure 3: Physical or psychological problems faced by drug addicts

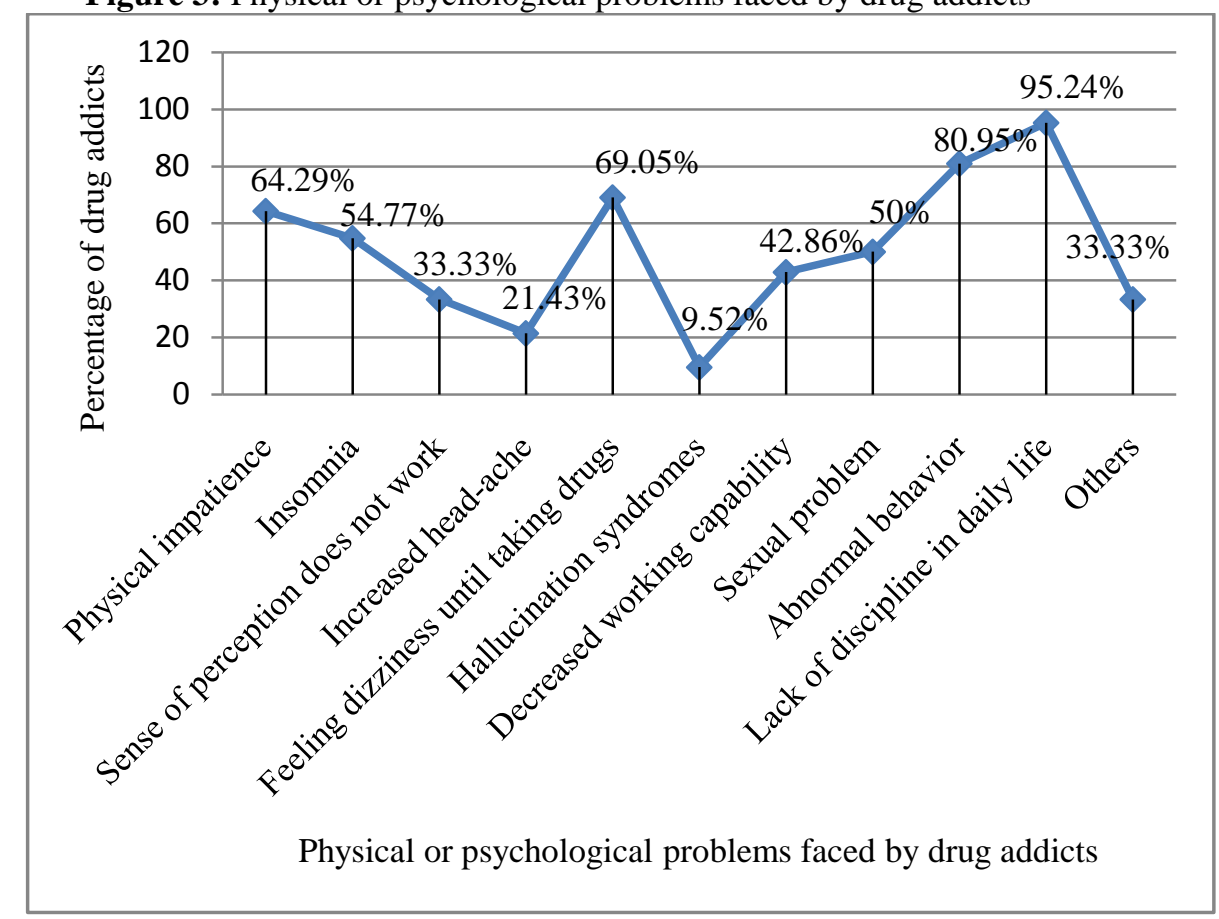

The findings revealed that about $95.24 \%$ felt that lack of discipline in their daily life was due to drug addiction. The study also depicted that $80.95 \%$ of the drug addicts behaved abnormally due to their addiction to drugs. Similarly, about $69.05 \%$ of the drug addicts felt dizziness until they were taking drugs. About $50 \%$ drug addicts have experienced the sexual problems because of taking drugs. About $33.33 \%$ faced some physical problems like kidney problem, lungs problem, heart disease, paralysis and psychological problem of addiction to pornography etc.

\section{CONCLUSION AND RECOMMENDATION}

Drug addiction has threatened the lives of the youth. Day-by-day the most productive youth young generation of our country are getting involved with the drug addiction. Like other parts of our country, drug addiction among youths is one of the major problems of Sylhet city and now-a-days it's started spreading 
everywhere. So, it is urgent to take necessary initiatives to get relief from the destruction of this disastrous habit. From the analytical discussion, it is clear that curiosity on drugs is the main reason behind the involvement of youth in drug addiction. The rank order also shows that encouragement from friends is the second most identified cause of drug addiction among youth. For entertainment and personal interest on drugs, many youth individuals are also getting involved in drug addiction. Study also revealed that the highest number of drug addicts changed drugs one after another to feel the adventure in tasting different drugs. Besides these some social, physical and psychological problems of drug addiction were also identified. Drug addiction is responsible for lost wages, destruction of property, soaring health care costs and broken families. Addiction leads many people into downward spiral of hopelessness that in some cases ends fatally. Study showed that a large number of drug addicts were neglected by their family members and relatives. This makes them socially alienated. Sometimes negligence can make oneself more devastating and more addictive. There are some recommendations for effective programming to prevent and reduce drug addiction among the youth. First of all, self willingness to give up of taking drugs is the best way and strength for the youth. It may be an important initiative to buildup strength and self motivation among youth. Motivation can also come from both formal and informal agents, like, friends, family members, schools, colleges or other institutions. Parents have to spend adequate time with their children, especially in urban areas where most of them are employed. Parental monitoring must be increased about the children's behavior, their partner, where they go, when they go and returned to home etc. Family members, relatives and friends must encourage and influence them positively so that they can come back from addiction. For this, there must have dissemination of the authentic information about negative consequences of drug abuse among them. There should have direct involvement of different government and development practitioners who will work with drug addicts not only for short term basis but for long term treatment and caring. Assurance of normal life can act as a tonic for drug addicts. If they are assured that they will be placed in a secured place after recovery, then it will be easier. Treatment and rehabilitation centers, who have been working for the treatment of drug addicts, their maintenance environment should be improved and skilled medical personnel should be appointed. Finally, media coverage can play a crucial role in creating awareness among youth about the devastating effects of drug addiction.

\section{REFERENCES}

[1] Bays, J. (1990). Substance addiction and child addiction: Impact of addiction on the child. Pediatric Clinics of North America, 37(4), 881-904.

[2] Bawkin H. \& R. Bawkin, (1972). Behaviour Disorders in Children. London: W.B. Saunders.

[3] Brookoff, D., O’Brien, K.K., \& Cook, C. S. (1997). Characteristics of participants in domestic violence. Journal of the American Medical Association, 277, 1369-1373.

[4] Davis, S. (1994). Effects of Chemical dependency in parenting women. In R.R. Watson (Ed.), Drug and alcohol reviews: Addictive behaviors in women (5, 381-414). Totowa NJ: Humana Press.

[5] DNC (2013). Annual Drug Report of Bangladesh. Dhaka, Bangladesh, Pp. 17-31.

[6] Easton, C. J., Swan, S., \& Sinha, R. (2000). Prevalence of family violence in clients entering substance abuse treatment. Journal of Substance Abuse Treatment, 18, 23-28.

[7] Famularo, R., Kinscherff, R., \& Fenton (1992). Parental substance addiction and the nature of child maltreatment. Child Addiction\& Neglect, 16, 475-483.

[8] Gall, M. D., \& Gall, J. P. (1996). Educational research: An introduction. White Plains, NY: Longman.

[9] Harrier, L. K., Lambert, P. L., \& Ramos, V. (2001). Indicators of adolescent drug users in a clinical population. Journal of Child and Adolescent Substance Addiction, 10(3), 71-87.

[10] Hurley, D.L. (1991). Women, alcohol and incest: An analytical review. Journal of studies on alcohol, 52 , 253-268.

[11] Isah, A. M. (2007). Drug Addiction/Addicts in the society, the role of counselling psychologist. Sokoto Education Review, 9 (1), 122-132.

[12] Kothari, C. R. (1988). Research Methodology: Methods \& Techniques, New Delhi: Wiley Publication.

[13] Pandit, J. C. \& Basak, N. C. (2013). Constraints faced by the farmers in commercial cultivation of vegetables. Journal of Bangladesh Agricultural University.11(2), 193-198.

[14] Semidei J, Radel LF \& Nolan C. (2001). Substance addiction and child welfare: Clear linkages and promising responses. Child Welfare, 80, 109-128.

[15] Sheridan, M. J. (1995). A proposed international model of substance addiction family functioning, and addiction/neglect. Child addiction \& neglect, 19, 519-530.

[16] World Drug Report (2010). United Nations Drugs Control Program (UNDCP). Executive Summary, United Nations Publication. 